\title{
Loss of Ep-CAM (COI7-IA) expression predicts survival in patients with gastric cancer
}

\author{
I Songun', SV Litvinov², CJH van de Velde', ST Pals ${ }^{3}$, J Hermans ${ }^{4}$ and JHJM van Krieken,5 \\ 'Department of Surgery, Leiden University Medical Center, PO Box 9600, 2300 RC Leiden, The Netherlands; '2 Department of Pathology, Leiden \\ University Medical Center, PO Box 9600, 2300 RC Leiden, The Netherlands; ${ }^{3}$ Department of Pathology, Academic Medical Center, PO Box 22660, \\ I 100 DD Amsterdam, The Netherlands; ${ }^{4}$ Department of Medical Statistics, Leiden University Medical Center, PO Box 9600,2300 RC Leiden, The \\ Netherlands; ${ }^{5}$ Department of Pathology, Radbond University, Nijmegen Medical Center, PO Box 910 I, 6500 HB Nijimegen, The Netherlands
}

Preoperative staging of gastric cancer is difficult and not optimal. The TNM stage is an important prognostic factor, but it can only be assessed reliably after surgery. Therefore, there is need for additional, reliable prognostic factors that can be determined preoperatively in order to select patients who might benefit from (neo) adjuvant treatment. Expression of immunohistochemical markers was demonstrated to be associated with tumour progression and metastasis. The expression of p53, CD44 (splice variants v5, v6 and v9), E-cadherin, Ep-CAM (CO I7-I A antigen) and c-erB2/neu were investigated in tumour tissues of 300 patients from the Dutch Gastric Cancer Trial, investigating the value of extended lymphadenectomy compared to that of limited lymphadenectomy). The expression of tumour markers was analysed with respect to patient survival. Patients without loss of Ep-CAM-expression of tumour cells (19\%) had a significantly better I 0 -year survival $(P<0.000$ I) compared to patients with any loss: $42 \%$ (s.e. $=7 \%)$ vs $22 \%$ $($ s.e. $=3 \%$ ). Patients with CD44v6 (VFFI8) expression in more than $25 \%$ of the tumour cells (69\% of the patients) also had a significantly better survival $(P=0.01)$ compared to patients with expression in less than $25 \%$ of the tumour cells: 10 year survival rate of $29 \%$ (s.e. $=3 \%$ ) vs $19 \%$ (s.e. $=4 \%$ ). The prognostic value of both markers was stronger in stages I and II, and independent of the TNM stage. Ep-CAM and CD44v6-expression provides prognostic information additional to the TNM stage. Loss of Ep-CAMexpression identifies aggressive tumours especially in patients with stage I and II disease. This information may be helpful in selecting patients suitable for surgery or for additional treatment pre- or postoperatively.

British Journal of Cancer (2005) 92, 1767-1772. doi: I0.1038/sj.bjc.66025 I9 www.bjcancer.com

(c) 2005 Cancer Research UK

Keywords: Ep-CAM; CD44; immunohistochemistry; prognostic factor; survival; gastric cancer

Patients with gastric carcinoma have a poor prognosis, especially the patients with an advanced stage disease (Allum et al, 1989; Akoh et al, 1991; Wanebo et al, 1993). In TNM stages I and II, better survival rates are seen after a curative resection: 5 year survival rates of $83-99 \%$ for stage I and $48-70 \%$ in stage II (Miwa, Japanese Research Society for Gastric Cancer, 1984; Hermanek, 1985). The TNM stage thus is an important prognostic factor, but it can be assessed reliably only after surgery and is therefore of no use for patient selection before surgery. Furthermore, within stages I and II, a significant number of patients will suffer from recurrent disease. Especially within this group there is a need for additional prognostic factors that can be determined preoperatively. Such factors are potentially helpful in identifying patients that might benefit from additional therapeutic modalities, either pre- or postoperatively (Yu et al, 1998; Hermans et al, 1999).

The process of carcinogenesis and metastasis is complex. Since we were interested in factors, which can predict whether the tumour is beyond cure by surgery alone, we reasoned that

*Correspondence: $\mathrm{Dr} \mathrm{H}$ van Krieken, Department of Pathology, Radbond University, Nijmegen Medical Center, PO Box 910I, 6500 HB Nijmegen, The Netherlands; E-mail: j.vankrieken@pathol.umcn.nl Received 16 August 2004; revised 7 February 2005; accepted 21 February 2005 especially molecules involved in cell-cell and cell-extracellular matrix (ECM) interactions might be of high relevance. CD44, a hyaluronate receptor, is involved in cell migration through the ECM, which can be viewed as highly relevant for tumour invasion and metastasis. Previous studies have indicated that CD44 isoform expression may be related to gastric tumour progression and poor prognosis for the patient (Heider et al, 1993; Mayer et al, 1993; Mulder et al, 1994; Terpe et al, 1994; Günthert et al, 1995). Given the fact that progression of tumours is modulated by changes in cell-cell interactions of the progressing tumour clones, we especially focused on the expression of Ep-CAM, an epithelial cell adhesion molecule, involved in regulation of cadherin adhesions, and, possibly, cell proliferation and invasion (Litvinov et al, 1994a, b; Litvinov, 1995). Furthermore, we analysed whether the expression of two molecules often involved in gastric cancer, p53 (involved in cell cycle control and apoptosis, and often overexpressed when mutations are present) and neu (or erbB2, a receptor tyrosine kinase that can be overexpressed due to the gene amplification, Falck and Gullick, 1989; Houldsworth et al, 1990) might be associated with prognosis in gastric cancer, even though they are presumably associated with early events in gastric carcinogenesis.

Evaluation of prognostic factors has to be based on high quality clinical and pathological data. In the Netherlands, a prospectively 
randomised, multicenter trial was conducted to compare the therapeutic efficacy of extended lymph node dissection with limited lymph node dissection in patients with gastric cancer (Bonenkamp et al, 1995, 1999). Strict quality control measures were taken to obtain optimal lymph node retrieval and thus postoperative staging. The prospectively collected clinical and pathology data from this trial form an optimal basis to evaluate the usefulness of prognostic value of immunohistochemically determined protein expression in tumour cells.

\section{MATERIAL AND METHODS}

\section{Patient selection}

Between August 1989 and July 1993 a prospective randomised multicenter trial was conducted in the Netherlands (Dutch Gastric Cancer Trial, DGCT) to compare the therapeutic efficacy of extended lymph node dissection (N1 and N2 levels, so-called D2) with that of limited lymph node dissection (N1 level, so-called D1) in patients with gastric cancer, operated on with curative intent (R0). For these patients (criteria for curative resectability were published earlier, Bonenkamp et al, 1995, 1999), presence of nodal involvement was assessed histologically and the pathologist recorded the actual number and location of the lymph nodes retrieved. Follow-up of the patients is at least 10 years.

In the present study, tumour tissue of 300 patients was used. Selection of these patients was based on the hospitals entering the largest number of patients, in order to have minimal variability in preparation and preservation of patient material used in this study.

\section{Immunohistochemistry}

In order to evaluate protein expression in adenocarcinoma of the stomach, formalin-fixed, paraffin-embedded tissue blocks of the primary tumour were used. According to the allocated treatment, the specimens were obtained by D1 or D2 resection. If a curative resection in intent was not possible, a palliative procedure was performed. From each resection specimen one tissue block was selected that contained the largest amount of tumour.

Sections $(4-\mu \mathrm{m}$ thick) were cut from formalin-fixed, paraffinembedded tissue blocks, mounted on precoated slides and kept at $37^{\circ} \mathrm{C}$ overnight. All paraffin sections were dewaxed in xylol for $20 \mathrm{~min}$ and endogenous peroxidase activity was blocked by methanol $/ \mathrm{H}_{2} \mathrm{O}_{2}$.

The monoclonal antibodies of the following specificities were used: cell cycle regulator p53 (mAb NCL-p53-DO7, Novocastra Laboratories Ltd), Ep-CAM (mAb 323/A3, Centocor, Malvern, PA, USA), E-Cadherin (mAb HECD-1, Thamer Diagnostica B.V.), CD44, splice variant v5 (VFF8), v6 (VFF7 and VFF18) ${ }^{9}$, and v9 (all from Bender Co., Vienna, Austria) and neu (Department of Pathology, Leiden). In negative controls, the primary antibody was replaced by phosphate-buffered saline (PBS).

For Ep-CAM staining, the sections were pretreated with a trypsin-solution $\left(0.1 \%\right.$ trypsin with $\left.0.1 \% \mathrm{CaCl}_{2}\right), \mathrm{pH} 7.4$, at $37^{\circ} \mathrm{C}$ for $20 \mathrm{~min}$. For p53, E-cadherin, CD44 variants and neu staining, the sections were pretreated by microwave in citrate buffer $(\mathrm{pH}$ 6.0) for $25 \mathrm{~min}$. The pretreated sections were rinsed in PBS and blocked by normal goat serum to reduce nonspecific antibody binding. The primary antibody was then applied and incubated overnight in its optimal dilutions in $\mathrm{PBS} / 1 \%$ bovine serum albumin (BSA).

The sections were washed with PBS prior to incubation with the secondary antibody. Then, a double step detection system was used: biotinylated rabbit anti-mouse (RAM) IgG was followed by streptavidin-biotin-complex ${ }^{\mathrm{HRP}}$ (sABC); each incubation was for $45 \mathrm{~min}$. The slides were stained with $3,3^{\prime}$-diaminobenzidine $/ \mathrm{H}_{2} \mathrm{O}_{2}$ (DAB) solution, and counterstained with Mayer's haematoxylin.

\section{Scoring of the sections}

The expression of the proteins was scored according to the estimated percentage tumour cells in the total tissue section showing positive staining. For each marker a scoring system was developed after initial screening of the variation of expression of each marker and taking systems used in the literature in account. This resulted in the following categories: p53 (0: $0-10 \% ; 1: \geqslant 10-$ $100 \%)$; VFF8, VFF7 and NEU (0: negative; 1 : positive); CD44v9 (0: $0-5 \%$; $1: \geqslant 5-100 \%)$; VFF18 (0: $0-25 \% ; 1: \geqslant 25-100 \%)$; ECadherin $(0:<50 \% ; 1: \geqslant 50 \%)$ and Ep-CAM (0: negative; $1: 1-$ $99 \% ; 2: 100 \%)$.

The scoring was done by two independent observers (IS and JHJMvK). Discrepancies were solved and consensus was reached by using a double-headed microscope. Incidentally, the marker scorings could not be performed because of missing material. Clinical data were provided after obtaining immunohistochemical results.

\section{Statistical analysis}

For statistical analysis the SPSS program was used. Kaplan-Meier survival curves are compared using the log-rank test. Cox's

Table I TNM stage and marker expression related to overall survival

\begin{tabular}{|c|c|c|c|c|c|}
\hline \multirow[b]{2}{*}{ Marker expression } & \multirow[b]{2}{*}{$n$} & \multirow[b]{2}{*}{ (\%) } & \multicolumn{2}{|c|}{ Overall survival } & \multirow[b]{2}{*}{$\begin{array}{c}\text { P-value } \\
\text { (log-rank) }\end{array}$} \\
\hline & & & $\begin{array}{c}5 \text { year } \\
\%\end{array}$ & $\begin{array}{c}10 \text { year } \\
\%\end{array}$ & \\
\hline \multicolumn{6}{|l|}{ TNM-stage $(n=285)$} \\
\hline I & 97 & (34) & 74 & 58 & \\
\hline$\|$ & 61 & $(21)$ & 36 & 26 & \\
\hline III & 76 & (27) & 12 & 6 & $<0.001$ \\
\hline IV & 50 & $(18)$ & 6 & 4 & \\
\hline \multicolumn{6}{|l|}{$p 53(n=286)$} \\
\hline $0-10 \%$ positive & 146 & $(5 \mathrm{I})$ & 36 & 27 & \\
\hline$\geqslant 10 \%$ positive & 140 & $(49)$ & 35 & 25 & 0.85 \\
\hline \multicolumn{6}{|l|}{$\operatorname{CD} 44 \vee 9(n=286)$} \\
\hline $0-5 \%$ positive & 148 & $(52)$ & 37 & 27 & \\
\hline$\geqslant 5 \%$ positive & 138 & $(48)$ & 33 & 25 & 0.23 \\
\hline \multicolumn{6}{|l|}{ VFF8 $(v 5)(n=282)$} \\
\hline Negative & 115 & $(4 I)$ & 35 & 24 & \\
\hline Positive & 167 & (59) & 36 & 27 & 0.84 \\
\hline \multicolumn{6}{|l|}{ VFFI8 (v6) $(n=285)$} \\
\hline $0-25 \%$ positive & 89 & $(3 \mid)$ & 24 & 19 & \\
\hline $26-100 \%$ positive & 196 & (69) & 41 & 29 & 0.01 \\
\hline \multicolumn{6}{|l|}{ VFF7 $(v 6)(n=284)$} \\
\hline Negative & 220 & (78) & 38 & 28 & \\
\hline Positive & 64 & (22) & 27 & 19 & 0.11 \\
\hline \multicolumn{6}{|l|}{$\operatorname{NEU}(n=289)$} \\
\hline Negative & 263 & $(91)$ & 35 & 26 & \\
\hline Positive & 26 & (9) & 31 & 23 & 0.98 \\
\hline \multicolumn{6}{|l|}{ E-Cadherin $(n=28 I)$} \\
\hline 0-49\% positive & 146 & (52) & 34 & 25 & \\
\hline $50-\quad 100 \%$ positive & 135 & $(48)$ & 35 & 24 & 0.63 \\
\hline \multicolumn{6}{|l|}{ Ep-CAM $(n=280)$} \\
\hline Negative & 20 & (7) & 10 & 5 & \\
\hline I-99\% positive & 208 & (74) & 32 & 22 & $<0.001$ \\
\hline I00\% positive & 52 & (19) & 54 & 42 & \\
\hline
\end{tabular}


regression was used to study the prognostic value for survival of tumour marker combinations. Differences were considered statistically significant, when the $P$-value was less than 0.05 .

\section{RESULTS}

The study group consisted of 181 male and 119 female patients. Mean age was 64.7 years (range $31-84$ ). Of these patients, 154 received a D1 and 146 D2 lymphadenectomy; 254 patients (85\%) had a resection with curative intent and the remaining 46 patients (15\%) had noncurative procedures. As expected, the TNM stage (not always available in noncurative procedures) was highly prognostic (see Table 1).
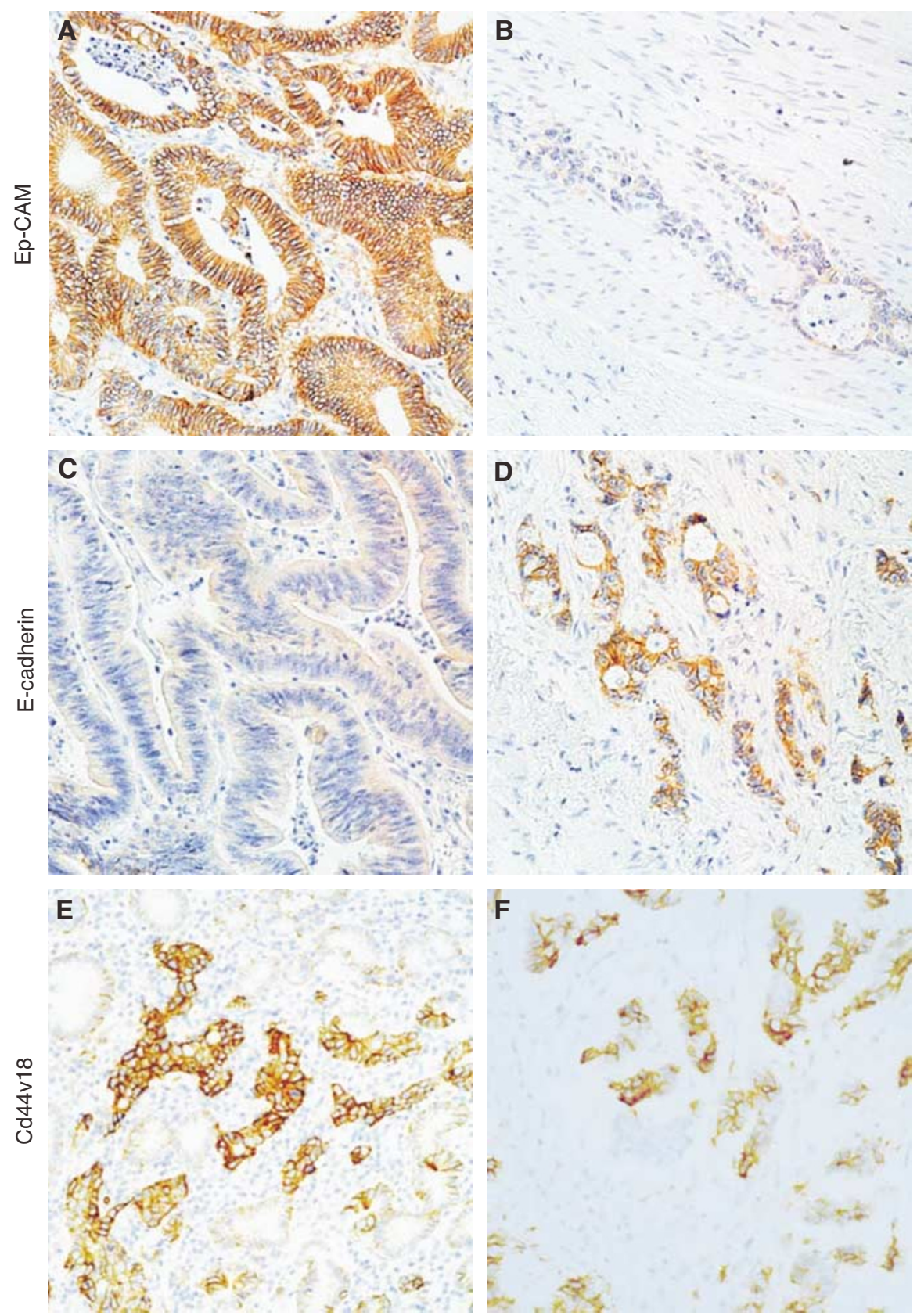

Based on univariate analyses of the original scoring of the markers, all marker expressions were dichotomised into more or less equal groups. Only Ep-CAM is divided into three groups: 1, negative; 2 , any loss of expression (1-99\% positive) and 3, no loss of expression (100\% positive). The results are reported in Table 1.

Examples of the staining patterns for E-cadherin and CD44v6 are shown in Figure 1.

From all the markers tested, only CD44v6 (VFF18 antibody) and Ep-CAM had a statistically significant prognostic value for survival (see Table 1 and Figures 2 and 3).

As a curative resection in intent is an important prognostic factor itself, we analysed this group separately. Again, only the TNM stage, CD44v6 (VFF18) and Ep-CAM had a strong prognostic value (Table 2 ). 


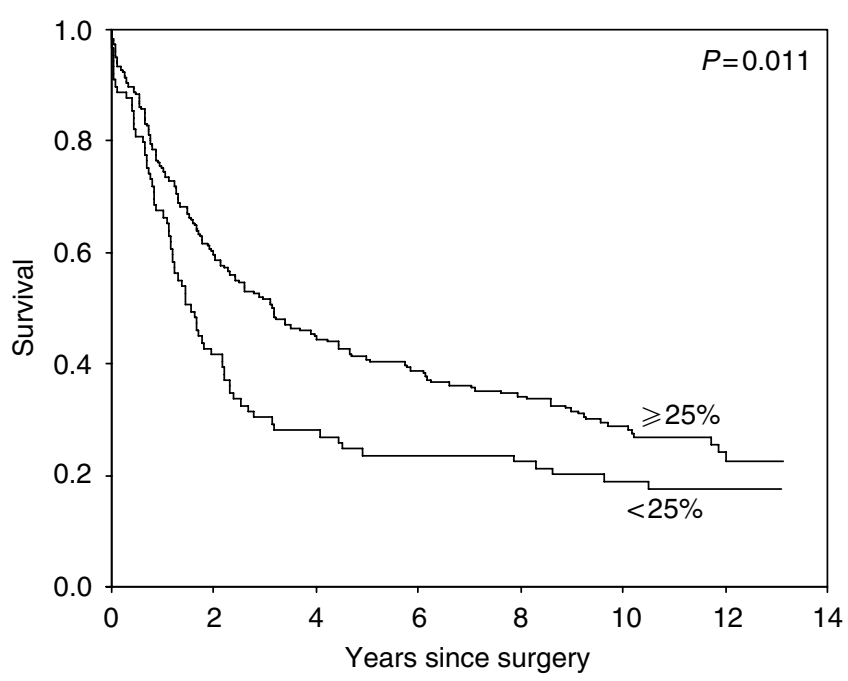

Figure 2 Survival of patients in whom more than $25 \%$ of the tumour cells stain for CD44v6 (VFFI8) compared to those with less staining.

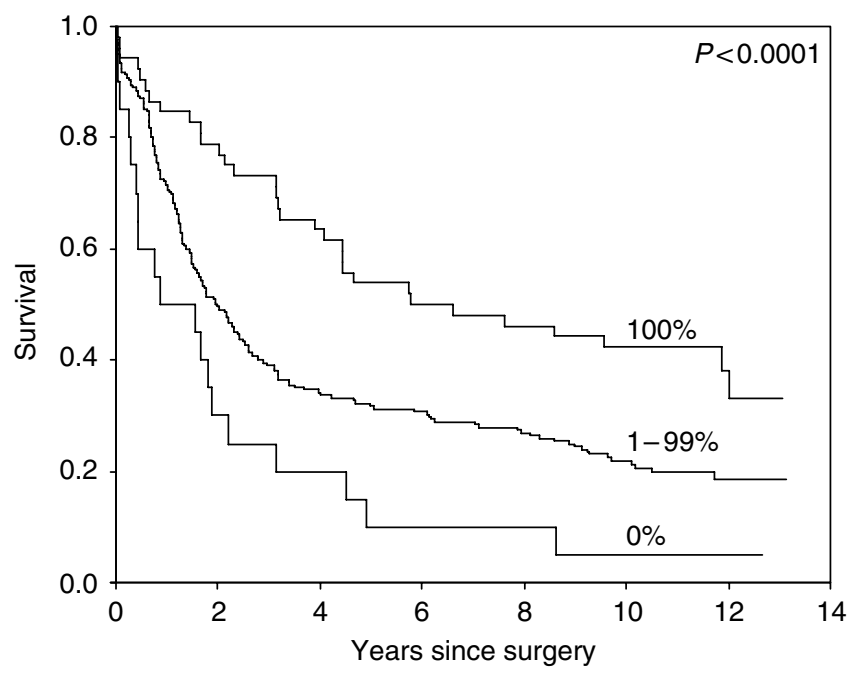

Figure 3 Survival curves of the three groups of patients with no staining for Ep-CAM compared to those with no loss and the intermediate group.

Table 2 Association between TNM stage, VFFI8 and Ep-CAM expression and survival in patients with a curative resection in intent

\begin{tabular}{|c|c|c|c|c|c|}
\hline & \multirow[b]{2}{*}{$N$} & \multirow[b]{2}{*}{ (\%) } & \multicolumn{2}{|c|}{ Overall survival } & \multirow{2}{*}{$\begin{array}{c}\text { P-value } \\
\text { (log-rank) }\end{array}$} \\
\hline & & & 5 year $\%$ & 10 year $\%$ & \\
\hline \multicolumn{6}{|c|}{ TNM-stage $(n=251)$} \\
\hline I & 97 & (39) & 73 & 58 & \\
\hline ॥ & 61 & (25) & 36 & 26 & \\
\hline III & 77 & (30) & 12 & 6 & \\
\hline IV & 16 & (6) & 19 & 13 & $<0.0001$ \\
\hline \multicolumn{6}{|c|}{ VFFI8 $(n=240)$} \\
\hline $0-25 \%$ & 74 & $(31)$ & 28 & 23 & \\
\hline $26-100 \%$ & 166 & (69) & 48 & 34 & 0.01 \\
\hline \multicolumn{6}{|c|}{ Ep-CAM $(n=236)$} \\
\hline 0 & 15 & (6) & 13 & 7 & \\
\hline ।-99\% & 174 & (74) & 38 & 26 & $<0.001$ \\
\hline $100 \%$ & 47 & (20) & 60 & 47 & \\
\hline
\end{tabular}

The prognostic value of the markers was studied additional to the TNM stage with a stepwise Cox's regression analysis. For this analysis the TNM stage was dichotomised into stages I+ II vs stages III + IV. Both CD44v6 (VFF18) and Ep-CAM were selected

Table 3 Cox's regression analysis applied on TNM stage, VFFI 8 and EpCAM expression $(n=25 \mathrm{I})$

\begin{tabular}{lccc}
\hline & $\mathbf{R R}$ & $\mathbf{9 5 \%} \mathbf{C l}$ & $\boldsymbol{P}$-value \\
\hline $\begin{array}{l}\text { TNM stage } \\
\text { I+II } \\
\text { III+IV }\end{array}$ & 1.00 & $2.27-4.29$ & $<0.001$ \\
VFFI & 3.12 & $1.01-2.00$ & 0.04 \\
$26-100 \%$ & & & \\
$0-25 \%$ & 1.00 & $0.99-2.31$ & 0.05 \\
Ep-CAM & 1.42 & $0.96-4.14$ & 0.06 \\
I00\% & & & \\
I-99\% & 1.00 & & \\
$0 \%$ & 1.51 & & \\
\hline
\end{tabular}
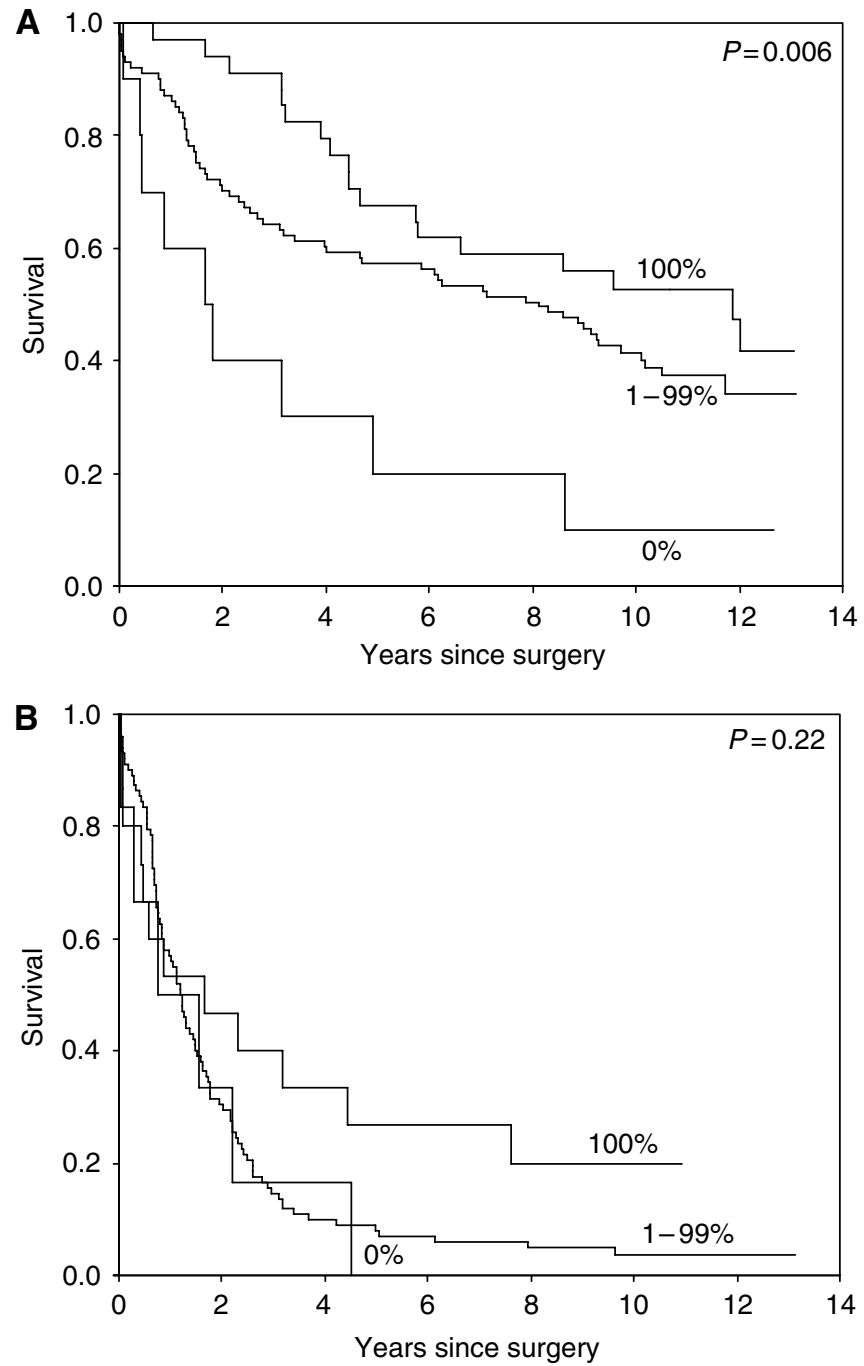

Figure 4 (A) Survival curve of the three groups divided by Ep-CAM staining for stages I+ II patients only, showing that even patients with low stage disease, but with complete loss op Ep-CAM have very poor prognosis. (B) Survival curve of the three groups divided by Ep-CAM staining for stages III + IV patients only, showing no significant differences. 


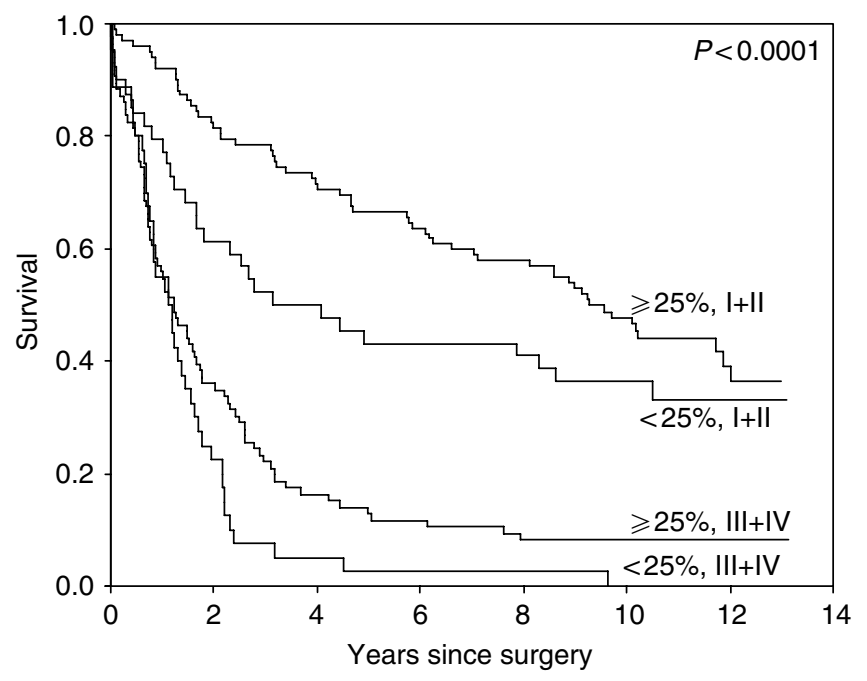

Figure 5 Survival curve of the three groups divided by Ep-CAM staining for stages III + IV patients only. Survival of patients by stage divided in those with less than 25\% tumour cells staining for CD44v6 (VFF I8) compared to those with more than $25 \%$ of the tumour cells staining, showing that the prognostic impact is independent of stage.

as having a significant prognostic value additional to the TNM stage (Table 3).

The prognostic value of the markers is especially evident in the stages I and II, see Figure 4A. In stages III and IV, the survival rates are very poor, so Ep-CAM expression cannot reach a statistically significant difference between the groups, see Figure 4B. Also, CD44v6 (VFF18) expression has prognostic relevance especially in early stages, see Figure 5 .

\section{DISCUSSION}

Our study demonstrates that loss of Ep-CAM and CD44v6 (VFF18) expression in gastric cancer has additional prognostic value to the TNM stage. If confirmed, these findings can be helpful in selecting patients for (neo-)adjuvant therapy for gastric cancer ( $\mathrm{Yu}$ et al, 1998; Hermans et al, 1999).

Although Ep-CAM is present in many epithelial cell types, some, like squamous epithelia express this molecule only in embryogenesis or in neoplasia (reviewed by Litvinov, 1995). In gastric epithelium the expression of Ep-CAM is low, and its increase is associated with very early stages of development of intestinal metaplasia (unpublished data). However, Ep-CAM loss associated with poor prognosis, as demonstrated in our earlier (Songun et al, 1996) and the present study, differs from previous observations of increased Ep-CAM expression associated with poor prognosis in breast cancer (Mirecka et al, 1995). Although not very strong, EpCAM mediated adhesions were able to suppress the scattering of cells embedded into matrigel (Litvinov, 1995). It was also demonstrated that in carcinoma cells with low levels of E-cadherin, a role for Ep-CAM adhesions in interconnecting cells is increasing (Tandon et al, 1990; Basak et al, 1998). Basak et al (1998) showed that in a model system Ep-CAM mediated adhesion can suppress invasion of tumour cells grafted in mice. Therefore, it seems quite possible that Ep-CAM negative cells are greatly reduced in means of cell-cell adhesion, which promotes their metastasis. However, we did not find a prognostic impact for E-cadherin expression, in concordance with findings in colorectal cancer (Van der Wurff et al, 1992, 1997). No studies have been carried out on gastric cancer previously, except for hereditary diffuse gastric cancer, which is extremely rare (Suriano et al, 2003).

CD44 is a highly glycosylated cell surface molecule, which is involved in cell-cell and cell-matrix interactions (Haynes et al, 1989, 1991). It was proven that transfection with cDNA encoding one isoform of CD44 converted nonmetastatic carcinoma and sarcoma rat cells into metastatic cells (Günthert et al, 1991). In human, high CD44 expression was shown to correlate with tumour dissemination and poor prognosis in diffuse large cell lymphoma and in colorectal carcinoma (Koopman et al, 1993; Mulder et al, 1994). CD44 variants containing v6 were also upregulated in activated lymphocytes (Koopman et al, 1993). However, it was also reported that CD44v6 is downregulated in tumours of squamocellular origin. Also, better differentiated carcinomas displayed more intense reactivity than more undifferentiated ones (Salmi et al, 1993). Our data are in line with previous studies (Mirecka et al, 1995; Muller et al, 1997). Both in the latter studies and in our study there was no association between CD44v6 expression (with VFF18) and presence of lymph node metastasis or tumour stage (data not shown). Our results suggest that CD44v6 would not be responsible for invasive growth and metastasis formation. They rather suggest that CD44v6 containing tumours behave less aggressively, illustrated by the fact that they are associated with significantly better survival. However, the VFF7 antibody, which is less sensitive in detecting CD44v6, was staining far fewer tumour cells and its expression was less strong compared to the VFF18 antibody. This shows the importance of selection of the right antibodies in studies like the present one.

The large amount of studies on p53 as prognostic marker gives very variable results. Our study, using just immunohistochemistry, the only generally applicable method, does not show clinical relevance. Our findings suggest the following biological implications: loss of p53 protein or E-cadherin is an early event during oncogenesis and therefore not predictive of a metastatic behaviour (Van der Wurff et al, 1992), whereas CD44 (v6) and Ep-CAM are late events, since Ep-CAM is positive in lymph node metastasis in patients with loss of Ep-CAM at the invasive front (unpublished observations). This suggests that the loss we observed is not a genetic defect, but rather reflects the complex interactions of angiogenesis, adhesion, matrix degradation and inflammation, which take place during the process of invasion and metastasis.

We have demonstrated that Ep-CAM and CD44v6 provide prognostic information additional to the TNM stage in a large series of gastric cancer patients with well documented, prospectively collected data from a randomised trial (Bonenkamp et al, 1995, 1999). Both CD44v6 and Ep-CAM expression may be helpful in identifying behaviour of gastric adenocarcinoma. This information may be helpful in selecting patients suitable for surgery or for additional treatment pre- or postoperatively. However, additional studies are required to establish the place of these markers in clinical management of patients with gastric cancer.

\section{REFERENCES}

Akoh JA, Sedgwick DM, Macintyre IMC (1991) Improving results in the treatment of gastric cancer: an 11-year audit. $B r J$ Surg 78: 349-351

Allum WH, Powell DJ, McConkey CC, Fielding JWL (1989) Gastric Cancer: a 25-year review. Br J Surg 76: 535-540
Basak S, Speicher D, Eck S, Wunner W, Maul G, Simmons MS, Herlyn D (1998) Colorectal carcinoma invasion inhibition by CO17-1A/GA733 antigen and its murine homologue. J Natl Cancer Inst 90: 691-697

Bonenkamp JJ, Hermans J, Sasako M, van deVelde CJH (1999) Extended lymph node dissection for gastric cancer. $N$ Engl J Med 340: 908-914 
Bonenkamp JJ, Songun I, Hermans J, Welvaart K, van de Velde CJH, Sasako M, Plukker JTM, van Elk P, Obertop H, Gouma DJ, Taat CW, van Lanschot J, Meyer S, de Graaf PW, von Meyenfeld MF, Tilanus H (1995) Randomized comparison of morbidity after D1 and D2 dissection for gastric cancer in 996 Dutch patients. Lancet 345: 745-748

Falck VG, Gullick WJ (1989) c-erbB-2 oncogene product staining in gastric adenocarcinoma. An immunohistochemical study. J Pathol 159: 107-111

Günthert BF, Liao H-X, Patton KL (1991) The transmembrane hyaluronate receptor (CD44): multiple functions, multiple forms. Cancer Cells 3: 347 - 350

Günthert U, Hoffmann M, Rudy W, Reber S, Zoller M, Haussman I, Matzku S, Wenzel A, Ponta H, Herrlich P (1991) A new variant of glycoprotein CD44 confers metastatic potential to rat carcinoma cells. Cell 65: 13-24

Günthert U, Stauder R, Mayer B, Terpe HJ, Finke L, Friedrichs K (1995) Are CD44 variants isoforms involved in human tumour progression? Cancer Surv 24: $19-24$

Haynes BF, Telen MJ, Hale LP, Denning SM (1989) CD44 - a molecule involved in leukocyte adherence and T-cell activation. Immunol Today 10: 423-428

Heider K-H, Dämmrich J, Skroch-Angel P, Muller-Hermelinck HK, Vollmers HP, Herrlich P, Ponta H (1993) Differential expression of CD44 splice variants in intestinal- and diffuse-type human gastric carcinomas and normal gastric mucosa. Cancer Res 53: 4197-4203

Hermanek P, Marnyama K, Sobin LH (1985) Prognostic factors in stomach cancer. In: Hermanck P, Gospodarowicz MK, Henson DE, Hutter RVP, Sobin LH (eds) Prognostic factor in cancer. Berlin: Springer, Verlag

Hermans J, Bonenkamp JJ, Boon MC, Bunt AMG, Lhyama S, Sasako M, van de Velde CJH (1999) Adjuvant therapy after curative resection for gastric cancer: meta-analysis of randomized trials. Classic Paper Curr Comments 3: $281-288$

Houldsworth J, Cordon-Cardo C, Ladanyi M, Kelsen DP, Chaganti RS (1990) Gene amplification in gastric and esophageal adenocarcinoma. Cancer Res 50: 6417-6422

Koopman G, Heider KH, Horst E, Adolf GR, van den Berg F, Ponta H, Herrlich P, Pals ST (1993) Activated human lymphocytes and aggressive non-Hodgkin's lymphomas express a homologue of the rat metastasisassociated variant of CD44. J Exp Med 177: 897-904

Litvinov SV (1995) Ep-CAM: a homophilic cell-cell adhesion molecule with EGF-like domains. Trends Glycosci Glycotechnol 7: 375-384

Litvinov SV, Bakker HAM, Gourevitch MM, Velders MP, Warnaar SO (1994b) Evidence for a role of the epithelial glycorotein 40 (Ep-CAM) in epithelial cell-cell adhesion. Cell Adhesion Commun 2: 417-428

Litvinov SV, Velders MP, Bakker HAM, Fleuren GJ, Warnaar SO (1994a) Ep-CAM: a human epithelial antigen is a homophilic cell-cell adhesion molecule. J Cell Biol 125: $437-446$

Mayer B, Jauch KW, Günthert U, Figdor CG, Schildberg FW, Funke I, Johnson JP (1993) De-novo expression of CD44 and survival in gastric cancer. Lancet 342: 1019-1022
Mirecka J, Marx D, Schauer A (1995) Immunohistochemical localization of CD44 variants 5 and 6 in human gastric mucosa and gastric cancer. Anticancer Res 15: 1459 - 1465

Miwa K, Japanese Research Society for Gastric Cancer (1984) Evaluation of the TNM classification of stomach cancer and proposal for its rational stage grouping. Jpn J Clin Oncol 14: 385-410

Mulder JWR, Kruyt PM, Sewnath M, Oosting J, Seldenrijk CA, Weidema WF, Offerhaus GJ, Pals ST (1994) Colorectal cancer prognosis and expression of exon-v6-containing CD44 proteins. Lancet 344: $1470-1472$

Muller W, Schneiders A, Heider KH, Meier S, Hommel G, Gabbert HE (1997) Expression and prognostic value of the CD44 splicing variants v5 and v6 in gastric cancer. J Pathol 183: 222-227

Salmi M, Grön-Virta K, Sointu P, Grenman R, Kalimo H, Jalkanen S (1993) Regulated expression of exon v6 containing isoforms of CD44 in man: downregulation during malignant transformation of tumors of squamocellular origin. J Cell Biol 122: $431-442$

Songun I, van de Velde CJ, Hermans J, Pals ST, Verspaget HW, Vis AN, Menon AG, Litvinov SV, van Krieken JH (1996) Expression of oncoproteins and the amount of eosinophilic and lymphocytic infiltrates can be used as prognostic factors in gastric cancer. Br J Cancer 74(11): $1783-1788$

Suriano G, Oliveira MJ, Huntsman D, Mateus AR, Ferreira P, Casares F, Oliveira C, Carneiro F, Machado JC, Mareel M, Seruca R (2003) Ecadherin germ line missence mutations and cell phenotype: evidence for the independence of cell invasion on the motile capabilities of the cells. Hum Mol Genet 12(22): $3007-3016$

Tandon AK, Clark GM, Chamness GC, McGuire WL (1990) Association of the 323/A3 surface glycoprotein with tumor characteristics and behavior in human breast cancer. Cancer Res 50: 3317-3321

Terpe H-J, Stark H, Prehm P, Günthert U (1994) CD44 variant isoforms are preferentially expressed in basal epithelia of non-malignant human fetal and adult tissues. Histochemistry 101: 79-89

Van der Wurff AA, ten Kate J, van der Linden EP, ten Kate J, Bosman FT (1992) L-CAM expression in normal, premalignant, and malignant mucosa. J Pathol 168(3): 287-291

Van der Wurff AA, Vermeulen SJ, van der Linden EP, Mareel MM, Bosman FT, Arends JW (1997) Patterns of alpha- and beta-catenin and Ecadherin expression in colorectal adenomas and carcinomas. J Pathol 182(3): $325-330$

Wanebo HJ, Kennedy BJ, Chmiel J, Steele Jr G, Winchester D, Osteen R (1993) Cancer of the stomach. A patient care study by the American College of Surgeons. Ann Surg 218: 583-592

Yu W, Whang I, Suh I, Averbach A, Chang D, Sugarbaker PH (1998) Prospective randomized trial of early postoperative intraperitoneal chemotherapy as an adjuvant to resectable gastric cancer. Ann Surg 3: $347-354$ 